\section{Impacto da deficiência intelectual moderada na dinâmica e na qualidade de vida familiar: um estudo clínico-qualitativo}

\author{
Impact of moderate intellectual disability on the \\ dynamics and quality of family life: a qualitative \\ clinical study
}

Impacto de la deficiencia intelectual moderada en la dinámica y calidad de vida familiar: un estudio clínico-cualitativo

\section{Resumo}

Este estudo clínico-qualitativo investigou o impacto da deficiência intelectual moderada na dinâmica e na qualidade de vida familiar. Os dados foram coletados por meio de entrevistas individuais com 15 mães de deficientes, escolhidas por conveniência, e examinados pela técnica de análise de conteúdo categorial temática. Os resultados foram discutidos usando-se abordagem compreensiva e interpretativa. Da análise das entrevistas apreendeu-se que o cuidado do filho deficiente é centrado na mãe, o que contribuiu para a modificação das relações familiares. O enfrentamento religioso apareceu como estratégia comum de ajuste. Os filhos deficientes tiveram acesso a menos serviços e suportes do que necessitavam, nas áreas de saúde, educação e lazer. Restrições financeiras e dificuldades no convívio comunitário impactaram negativamente na qualidade de vida familiar. Apoio emocional e psicológico para todos os membros da família, e apoio prático e social, incluindo distribuição de renda e acesso a serviços adequados, mostraram-se essenciais para o bem-estar do deficiente e de sua família.

Deficiência Intelectual; Relações Familiares; Pesquisa Qualitativa
Rodrigo Victor Viana Tomaz ${ }^{1}$

Vanessa de Arruda Santos 1

Lucimar Retto da Silva de Avó 1 Carla Maria Ramos Germano 1

Débora Gusmão Melo 1

doi: $10.1590 / 0102-311 \times 00096016$

\section{Correspondência}

D. G. Melo

Departamento de Medicina, Universidade Federal de São Carlos.

Rod. Washington Luís (SP-310) Km 235, Campus da UFSCar, São Carlos, SP 13565-905, Brasil.

debora.gusmao@gmail.com

1 Departamento de Medicina, Universidade Federal de São Carlos, São Carlos, Brasil. 


\section{Introdução}

Deficiência intelectual é um transtorno do desenvolvimento que inclui prejuízos intelectuais e adaptativos, nos domínios conceitual, social e prático. Seu diagnóstico implica déficits em funções intelectuais como raciocínio, resolução de problemas, planejamento, pensamento abstrato, julgamento, aprendizagem acadêmica e pela experiência; e déficits em funções adaptativas que resultam em fracasso para atingir padrões de desenvolvimento e socioculturais em relação à independência pessoal e responsabilidade social 1 .

Deficiência intelectual é um diagnóstico clínico presumível a partir dos cinco anos de idade, quando é possível mensurar adequadamente os déficits intelectuais e adaptativos. A expressão "atraso global do desenvolvimento" é tipicamente reservada para crianças menores, que fracassam em alcançar os marcos de desenvolvimento esperados, mas cuja gravidade dos déficits não pode ser avaliada de modo confiável. Crianças com atraso global do desenvolvimento requerem reavaliações periódicas, pois podem ou não evoluir com deficiência intelectual 1,2 .

Essa deficiência tem prevalência global estimada entre 1 e $3 \%$ e está presente como comorbidade em mais de 2.000 condições nosológicas distintas, incluindo muitas doenças genéticas raras 2,3. Dados do Censo Demográfico de 2010 indicam que 1,4\% da população brasileira possui algum grau de deficiência intelectual 4.

A deficiência intelectual pode ser classificada, com base no funcionamento adaptativo, em leve, moderada, grave ou profunda. O funcionamento intelectual de indivíduos com deficiência intelectual moderada é caracterizado por falhas de atenção, fluxo lento de ideias, erros perceptivos, pobreza de associações, dificuldade para abstração e síntese. Essas pessoas frequentemente apresentam dificuldades na expressão oral e na compreensão dos convencionalismos sociais. Costumam apresentar comportamento instável (ora dócil, ora turbulento) e semidependência nas atividades de vida diária. Apresentam desenvolvimento motor aceitável e podem adquirir conhecimentos básicos que permitam o trabalho. Contudo, dificilmente dominam com suficiência técnicas de leitura, escrita e cálculo 1.

As limitações cotidianas apresentadas pelos indivíduos com deficiência intelectual moderada imprimem demandas particulares para o pleno exercício da cidadania. Ações políticas e sociais que atendam a essas necessidades podem impactar positivamente na qualidade de vida dos deficientes e de suas famílias 5 .

Considerando que as famílias formam a estrutura principal para o funcionamento e a estabilidade das sociedades contemporâneas, emerge a concepção de qualidade de vida familiar 6 . A qualidade de vida familiar está baseada nos princípios da qualidade de vida individual, como holismo, bem-estar, relacionamentos e participação social e, conceitualmente, pode ser definida como um sentido dinâmico de bem-estar da família, percebido subjetivamente e informado por seus membros, no qual as necessidades individuais e familiares interagem 7 .

Segundo o modelo sistêmico, a família é um circuito complexo e integrado, que envolve indivíduos e meio ambiente, dentro do qual os membros são interdependentes e exercem influências recíprocas uns nos outros ${ }^{8}$. Assim, dado que o comportamento de cada pessoa é afetado pelo comportamento das outras pessoas da família, ter um membro com deficiência intelectual modifica a dinâmica familiar 9 .

Dinâmica familiar, num sentido amplo, está correlacionada à qualidade da vida em família na dimensão sistêmica, uma vez que integra processos relacionados à estrutura familiar, como os padrões de comunicação e interação intrafamiliar, os papéis e as hierarquias dos diferentes membros da família 10. Três principais aspectos interferem na dinâmica familiar e são moduladores do funcionamento e da capacidade de adaptação da família: os recursos disponíveis, a habilidade de comunicação e a sobrecarga de dificuldades a que se encontra sujeita. Sendo as famílias sistemas relativamente flexíveis, cabe a estas efetuar as mudanças necessárias para se ajustar às diversas situações e dificuldades que ocorrem ao longo das suas vidas, como, por exemplo, o nascimento de um filho deficiente 10,11. Contudo, o processo de adaptação à presença de um filho deficiente é complexo e nunca concluído, pois à proporção que o filho cresce, novas situações exigem novas adaptações 11 .

Reconhecendo a família como unidade de importância central no suporte à pessoa com deficiência, um grupo de especialistas criou o Family Quality of Life Survey 2006 (FQOLS-2006), um instrumento estruturado em nove domínios (saúde da família, bem-estar financeiro, relações familiares, 
apoio de outras pessoas, apoio de serviços relacionados com a deficiência, influência de valores que regem a família, carreira, lazer e recreação, e interação com a comunidade) que abarcam a totalidade dos assuntos que se mostraram relevantes em estudos prévios sobre qualidade de vida de famílias com membros deficientes 12,13. Alguns domínios da qualidade de vida familiar podem ser mais importantes que outros nessas famílias e, como potenciais preditores, salientam-se características sociodemográficas, idade do deficiente, tipo e extensão da deficiência 13,14,15.

Estudos sobre o impacto da deficiência intelectual no funcionamento e na qualidade de vida familiar têm relevância científica e social, pois revelam as dificuldades e estratégias de enfrentamento que as famílias utilizam para garantir o desenvolvimento de seus filhos. Uma melhor compreensão e atuação sobre esse processo pode contribuir para a integralidade do cuidado do deficiente e o bemestar de sua família. Nesse contexto, o presente estudo objetivou investigar o impacto da deficiência intelectual moderada na dinâmica e na qualidade de vida familiar.

\section{Metodologia}

\section{Cenário e desenho do estudo}

Este trabalho foi conduzido em São Carlos, cidade localizada no centro geográfico do Estado de São Paulo, no Sudeste do Brasil. São Carlos tem aproximadamente 230 mil habitantes e taxa geométrica de crescimento de cerca de 1\% ao ano. Em 2010, seu índice de desenvolvimento humano foi de 0,805, sendo considerado um município com nível elevado de riqueza e bons indicadores sociais 16 .

Esta é uma pesquisa exploratória, desenvolvida com metodologia clínico-qualitativa 17 . O método científico clínico-qualitativo abrange um conjunto de técnicas e procedimentos adequados para descrever e compreender os sentidos e significados dos fenômenos humanos relacionados ao processo saúde/doença. O acolhimento do indivíduo no setting de cuidados à saúde, a valorização das suas angústias e a manutenção de uma atitude clínica são elementos fundamentais desse método, que tem se mostrado particularmente útil na investigação de fenômenos complexos. Outras características são a preocupação com os significados conscientes e inconscientes atribuídos pelos sujeitos estudados aos diversos fenômenos vivenciados, e a necessidade do pesquisador possuir de antemão vivência prática e conhecimento teórico sobre o fenômeno estudado, preservando assim a natureza teórica e empírica como pontos simultâneos de partida da pesquisa. No método clínico-qualitativo o pesquisador compõe e reconstrói os fatos com base em fragmentos, utilizando-se de sua experiência e da multiplicidade de referenciais teóricos capazes de embasá-lo 18.

O presente texto corresponde à parte dos resultados de uma investigação mais ampla intitulada Qualidade de Vida de Famílias com Pacientes com Deficiência Intelectual, cuja produção de dados foi realizada em 2014. Este trabalho foi aprovado pelo Comitê de Ética em Pesquisa com Seres Humanos da Universidade Federal de São Carlos (UFSCar) e todas as participantes assinaram Termo de Consentimento Livre e Esclarecido (parecer no 444.917, de 4 de novembro de 2013).

\section{Características das participantes}

A população da pesquisa, definida por conveniência, foi composta por 15 mães de pacientes com deficiência intelectual moderada, acompanhados no Ambulatório de Genética Médica da UFSCar, sendo que quatro pacientes possuíam síndromes genéticas de microdeleção e nos demais onze pacientes a etiologia da deficiência intelectual não foi definida. Procurou-se incluir participantes com expressividade verbal suficiente para sustentar uma entrevista em profundidade, além de desejarem compartilhar suas impressões sobre a experiência de ter um filho com deficiência intelectual. $O$ fechamento do número amostral foi feito durante a análise dos dados por meio da técnica da saturação teórica 19,20. A Tabela 1 apresenta a caracterização sociodemográfica de cada entrevistada. 


\section{Tabela 1}

Caracterização sociodemográfica individual de cada entrevistada.

\begin{tabular}{|c|c|}
\hline Entrevistada & Características \\
\hline 1 & 35 anos, formação técnica, cabeleireira, branca, solteira, possui dois filhos, filho com deficiência intelectual com 15 anos \\
\hline 2 & 50 anos, Ensino Médio incompleto, manicure, parda, viúva, possui três filhos, filha com deficiência intelectual com 9 anos \\
\hline 3 & $\begin{array}{l}44 \text { anos, Ensino Superior completo, administradora de empresa, branca, casada, possui dois filhos, } \\
\text { filha com deficiência intelectual com } 13 \text { anos }\end{array}$ \\
\hline 4 & $\begin{array}{l}45 \text { anos, Ensino Fundamental incompleto, do lar, branca, casada, possui três filhos, } \\
\text { filho com deficiência intelectual com } 13 \text { anos }\end{array}$ \\
\hline 5 & $\begin{array}{l}48 \text { anos, Ensino Superior completo, professora, branca, relação estável, possui dois filhos, } \\
\text { filho com deficiência intelectual com } 7 \text { anos }\end{array}$ \\
\hline 6 & $\begin{array}{l}69 \text { anos, Ensino Fundamental completo, do lar, branca, casada, possui quatro filhos, } \\
\text { filho com deficiência intelectual com } 27 \text { anos }\end{array}$ \\
\hline 7 & $\begin{array}{l}41 \text { anos, Ensino Médio completo, do lar, branca, casada, possui três filhos, } \\
\text { filho com deficiência intelectual com } 19 \text { anos }\end{array}$ \\
\hline 8 & $\begin{array}{l}28 \text { anos, Ensino Médio incompleto, diarista, parda, relação estável, possui quatro filhos, } \\
\text { filha com deficiência intelectual com } 11 \text { anos }\end{array}$ \\
\hline 9 & $\begin{array}{l}54 \text { anos, Ensino Fundamental completo, servidora pública (merendeira), preta, casada, possui dois filhos, } \\
\text { filho com deficiência intelectual com } 16 \text { anos }\end{array}$ \\
\hline 10 & $\begin{array}{l}49 \text { anos, Ensino Médio completo, servidora pública (escriturária), branca, casada, possui dois filhos, } \\
\text { filha com deficiência intelectual com } 19 \text { anos }\end{array}$ \\
\hline 11 & 60 anos, Ensino Médio completo, do lar, branca, viúva, possui dois filhos, filha com deficiência intelectual com 26 anos \\
\hline 12 & $\begin{array}{l}40 \text { anos, Ensino Fundamental completo, autônoma (trabalha com artesanato), parda, relação estável, possui um filho, } \\
\text { filho com deficiência intelectual com } 19 \text { anos }\end{array}$ \\
\hline 13 & $\begin{array}{l}39 \text { anos, Ensino Médio incompleto, vigilante, parda, casada, possui dois filhos, } \\
\text { filho com deficiência intelectual com } 8 \text { anos }\end{array}$ \\
\hline 14 & $\begin{array}{l}45 \text { anos, pós-graduação stricto sensu, administradora de empresa, branca, casada, possui dois filhos, } \\
\text { filha com deficiência intelectual com } 11 \text { anos }\end{array}$ \\
\hline 15 & $\begin{array}{l}46 \text { anos, Ensino Fundamental incompleto, do lar, parda, casada, possui dois filhos, } \\
\text { filho com deficiência intelectual com } 16 \text { anos }\end{array}$ \\
\hline
\end{tabular}

\section{Coleta dos dados}

O perfil sociodemográfico das participantes foi investigado usando-se um questionário pré-definido com informações sobre idade, cor da pele, estado civil, escolaridade, trabalho e número de filhos. A coleta de dados foi feita por meio de entrevistas individuais semiestruturadas 21 , realizadas por pesquisadora previamente capacitada e após a realização de três entrevistas de aculturação. A questão disparadora das entrevistas foi: "Como a Senhora se sentiu quando percebeu que seu filho tinha um atraso?”. Com base nessa pergunta estimulou-se a livre reflexão e expressão das participantes. Como alguns tópicos que nos interessavam poderiam não ser espontaneamente mencionados, determinadas questões foram ativamente apresentadas, relativas a: relacionamento com familiares e comunidade, redes de apoio, acesso e satisfação com os sistemas de saúde e educação, impacto financeiro, carreira profissional e religiosidade.

As perguntas foram propostas com adaptação do léxico ao universo conceitual das participantes. O modo aberto de propor as questões, sem limite de tempo para respostas e comentários, permitiu um aprofundamento na expressão dos significados pessoais detidos por elas. As entrevistas foram gravadas e transcritas integralmente; os suportes auditivo e escrito constituíram o corpus da pesquisa. 


\section{Análise dos dados}

Para examinar o corpus foi adotada a técnica de análise de conteúdo categorial temática, tal como proposta por Bardin em 1977 22. A análise de conteúdo compreende um conjunto de técnicas de análise de comunicações baseado na linguística tradicional, na semântica e na hermenêutica. É uma estratégia largamente utilizada em pesquisas com metodologia qualitativa, objetivando a busca dos sentidos contidos em materiais como documentos ou entrevistas, almejando a produção de inferências 17,23. Desse modo, operacionalmente, foram realizadas as etapas de pré-análise das entrevistas, exploração e codificação do material, tratamento dos resultados com inferências e interpretações.

Para a análise foram definidas nove pré-categorias, em correspondência direta com os nove domínios do FQOLS-2006: (1) saúde da família, (2) bem-estar financeiro, (3) relações familiares, (4) apoio de outras pessoas, (5) apoio de serviços relacionados com a deficiência, (6) influência de valores que regem a família, (7) carreira, (8) lazer e recreação e (9) interação com a comunidade.

Uma vez definidas as pré-categorias, foi feita a codificação dos dados, desmembrando e reagrupando sistematicamente os conteúdos presentes nos depoimentos, que foram classificados e circunscritos em temas, de acordo com os seus significados.

As entrevistas foram analisadas e codificadas uma a uma, de forma independente e individual por três pesquisadores. Os aspectos convergentes e divergentes das análises individuais foram discutidos, desenvolvendo-se progressivamente a categorização temática final apresentada nos resultados. Com base na frequência de aparecimento, foram selecionados os principais temas, sendo excluídos os que apareceram em uma única entrevista. Por fim, os temas selecionados foram examinados e discutidos com subsídio da literatura e da experiência clínica dos autores, que empreenderam uma abordagem compreensiva e interpretativa.

\section{Resultados}

\section{Categorias e temas}

Com base na análise das 15 entrevistas foram selecionados 35 temas nas nove pré-categorias consideradas. Na Tabela 2, visualiza-se a distribuição desses temas: o número de ocasiões em que o tema ocorreu ao longo das 15 entrevistas é apresentado na coluna "frequência total"; na coluna "frequência nas entrevistas" é indicado o número de participantes que mencionaram o tema.

\section{Saúde da família}

Tanto o Sistema Único de Saúde (SUS) quanto o sistema suplementar foram considerados inadequados. Os serviços oferecidos pelo SUS foram caracterizados como contingenciais, com longas filas de espera, além da sensação de abandono e falta de transparência nas informações. O sistema de saúde suplementar foi apontado como um meio mais rápido para garantir assistência, apesar da imposição de regras de atendimento consideradas descabidas e limitantes para o cuidado em saúde.

"Quando nós fomos chamadas pra triagem na terapia ocupacional, depois de dois anos esperando, quando eu disse que ela já fazia atendimento particular, então a senhora me disse: 'se você tem condições de pagar, a gente não vai atendê-la"' (Entrevistada 3).

Muitos profissionais de saúde foram percebidos como despreparados para manejar a situação de deficiência intelectual, especialmente por desvalorizarem queixas relacionadas ao atraso no desenvolvimento neuropsicomotor, não reconhecerem a deficiência intelectual ou não saberem o que fazer diante da deficiência. De modo geral, os profissionais especialistas, com experiência clínica no cuidado de deficientes, foram considerados mais competentes, porém, particularmente nos cenários de atenção primária à saúde o cuidado foi percebido como precário. Uma decorrência direta da inadequação dos serviços foi a judicialização do sistema de saúde, prática eventualmente apontada como alternativa para a garantia de direitos.

"Eu passei por uma médica do postinho que falou pra mim que eu era louca e que eu tinha que colocar ele numa creche ou arrumar outro filho, porque a maneira como eu tratava ele, cheio de cuidados, cheio de mimos, 
Tabela 2

Distribuição dos 35 principais temas apreendidos em relação às nove pré-categorias, nas 15 entrevistas.

\section{Pré-categorias/Temas}

\section{Frequência Frequência nas \\ total entrevistas}

Saúde da família

O SUS é inadequado (serviço é contingencial - ora tem, ora não tem, há longas filas de espera, usuário

se sente abandonado, falta transparência de informações)

Profissionais de saúde são geralmente inadequados (desvalorizavam as queixas, não reconhecem a

deficiência intelectual ou não sabem o que fazer diante da deficiência intelectual)

Alguns profissionais de saúde são especialmente percebidos como mais adequados

Sistema de saúde suplementar garante atendimento mais ágil, mas também é inadequado (não há

cobertura para todos os procedimentos)

A situação de cuidadora de filho com deficiência intelectual gera estresse, promove doenças

Para conseguir assistência à saúde adequada briga/judicia

Bem-estar financeiro

Há gastos no orçamento doméstico com saúde e educação do filho com deficiência intelectual

Renda familiar é insuficiente para o cuidado do filho com deficiência intelectual (recebe ajuda financeira

ou benefícios sociais)

Insatisfação por não receber benefício social em função da renda familiar ser considerada alta

Há limitações financeiras - lazer e recreação são prejudicados em detrimento dos gastos com o filho

com deficiência intelectual

Relações familiares

Cuidado centrado na mãe - pai não aceita, não colabora ou discorda sobre como cuidar do filho com deficiência intelectual

Deficiência intelectual interferiu no planejamento familiar

Outros filhos ajudam na educação/cuidado do filho com deficiência intelectual

Outros filhos têm ciúmes da relação da mãe com o filho com deficiência intelectual

Filho com deficiência intelectual é particularmente carinhoso com a mãe e outros familiares

Cuidar do filho com deficiência intelectual é uma luta, uma batalha

Mãe pensa mais no filho com deficiência intelectual em detrimento de outros membros da família -

filho com deficiência intelectual é o centro da organização familiar

Apoio de outras pessoas

Ajuda conviver/desabafar com outras mães/familiares de crianças com deficiência intelectual

Não obtém ajuda profissional ou familiar para cuidar do filho - ninguém gosta de cuidar de criança

especial

Apoio de serviços relacionados com a deficiência

Sistema de educação é inadequado (não há inclusão e professores são despreparados)

Há insuficiência de serviços públicos de educação relacionados à deficiência intelectual

Considera que a APAE ajuda na educação do filho com deficiência intelectual

Considera que a APAE é inadequada para as necessidades educacionais do filho com deficiência

intelectual

Em busca de educação adequada já percorreu várias escolas, inclusive particulares (peregrinação escolar)

Influência de valores que regem a família

Confiança, crença, entrega, esperança na vontade/graça divina (as coisas são como Deus quer)

Dá graças a Deus pelo filho com deficiência intelectual (filho veio para melhorar a sua vida, dar sentido,

eixo)

Questionamento pela deficiência intelectual do filho (Por que eu? Por que comigo?)

Dá graças a Deus porque o filho tem somente deficiência intelectual moderada - poderia ser pior

(continua) 
Tabela 2 (continuação)

\begin{tabular}{|c|c|c|}
\hline Pré-categorias/Temas & $\begin{array}{l}\text { Frequência } \\
\text { total }\end{array}$ & $\begin{array}{c}\text { Frequência nas } \\
\text { entrevistas }\end{array}$ \\
\hline \multicolumn{3}{|l|}{ Carreira } \\
\hline $\begin{array}{l}\text { A necessidade de a mãe trabalhar fora de casa prejudica o cuidado do filho com deficiência intelectual e } \\
\text { vice-versa }\end{array}$ & 3 & 3 \\
\hline Mãe interrompeu a carreira profissional para cuidar do filho com deficiência intelectual & 3 & 2 \\
\hline \multicolumn{3}{|l|}{ Lazer e recreação } \\
\hline $\begin{array}{l}\text { Restrição nas atividades de lazer/recreação por causa das especificidades do filho com deficiência } \\
\text { intelectual (inclusive necessidade de supervisão) }\end{array}$ & 5 & 4 \\
\hline $\begin{array}{l}\text { Família se divide nas atividades de lazer e recreação para agradar a todos os membros (inclusive filhos } \\
\text { sem deficiência intelectual) }\end{array}$ & 3 & 2 \\
\hline \multicolumn{3}{|l|}{ Interação com a comunidade } \\
\hline Percebe preconceito na escola e no convívio social e comunitário & 24 & 8 \\
\hline $\begin{array}{l}\text { Comportamento considerado anômalo do filho com deficiência intelectual causa constrangimento/ } \\
\text { incômodo no convívio social }\end{array}$ & 11 & 9 \\
\hline
\end{tabular}

APAE: Associação de Pais e Amigos dos Excepcionais; SUS: Sistema Único de Saúde.

que tava estragando ele. Então eu comecei a achar que aquela médica tinha razão, porque se ele estava com dois anos e não andava a culpa era minha. Se ele não engatinhava, eu que não ensinei, eu que ficava com ele o tempo todo no colo pra ele não chorar" (Entrevistada 7).

A situação de cuidadora de um filho com deficiência intelectual moderada foi concebida ainda como geradora de estresse e fator de risco para adoecimento materno.

"Eu não tive mais paz depois que ele nasceu. Eu acho que eu envelheci uns vinte anos. Tanto no que diz respeito à questão emocional, quanto à questão física. Porque é difícil” (Entrevistada 5).

\section{Bem-estar financeiro}

Gastos financeiros relacionados com a assistência à saúde e educação foram constantemente relatados e, em última instância, atividades de lazer e recreação foram prejudicadas. A renda familiar foi percebida como insuficiente, complementada por pessoas fora do núcleo familiar e/ou por benefícios sociais. Famílias que não conseguiram benefício social em função da renda familiar ser considerada alta sentiram-se injustiçadas.

"O que eu gasto por mês de terapia podia estar investindo em outras coisas pra ela. Porque acaba que a gente busca só terapias, mas esquece um pouco do lazer" (Entrevistada 14).

\section{Relações familiares}

As relações familiares foram profundamente enredadas pela presença do filho deficiente, que foi alçado como centro da organização familiar. O cuidado desse filho esteve fortemente centrado na mãe, afetando a saúde materna, a relação do casal e o planejamento familiar. O pai foi frequentemente descrito como não colaborativo ou não confiável para a divisão do cuidado, inclusive por não aceitar a deficiência do filho. A experiência de ser cuidadora de um filho com necessidades especiais foi, muitas vezes, encarada como uma luta, compensada pelo vínculo desenvolvido com o filho deficiente. Houve relatos de reestruturação na organização familiar, com envolvimento dos demais filhos no cuidado do irmão deficiente, embora frequentemente os outros filhos manifestem ciúmes da relação materna com o filho com deficiência intelectual.

"O pai sai, vai trabalhar, vai fazer o papel dele. Aqui em casa, o pai sempre deu o maior apoio, mas sempre fui eu que fui nos médicos, sempre fui eu que fui nas escolas, sempre fui eu que fui exigir. Eu que fui nas terapias, fui na fonoaudióloga, psicóloga..." (Entrevistada 7).

"Ela é o centro do universo! Tudo gira em torno dela. Ela acaba tendo uma atenção muito maior, porque ela solicita a gente o tempo todo" (Entrevistada 3). 


\section{Apoio de outras pessoas}

Os temas apreendidos revelaram a importância de conviver com outras famílias que também vivenciam a experiência de ter um filho com deficiência intelectual, e reforçaram a ideia de que o cuidado do filho deficiente é centrado na mãe, uma vez que é difícil contar com apoio externo, ainda que profissional.

"Fui conhecer outras mães que tinham esse problema. Então isso me ajudou. Você conversa com um, você conversa com outro. Um fala uma coisa, outro fala outra. Aquela deficiência do filho de uma colega bate com a da gente. Então a gente vê que não está sozinha..." (Entrevistada 4).

\section{Apoio de serviços relacionados com a deficiência}

A inclusão escolar dos deficientes foi apontada como um nó crítico. As mães relataram insuficiência de serviços públicos de educação adequados para os deficientes, o que muitas vezes levou à peregrinação por várias escolas, inclusive particulares. Os profissionais de educação foram comumente apontados como despreparados e as particularidades de aprendizagem percebidas como pouco valorizadas.

Houve ambiguidade em relação ao papel educacional da Associação de Pais e Amigos dos Excepcionais (APAE). Por um lado, os professores foram considerados mais capacitados; por outro, a convivência com pessoas com deficiência intelectual de graus mais severos foi elencada como elemento que interferiu negativamente na aprendizagem e no comportamento.

"Até hoje eu tenho uma mágoa dentro de mim que eu não devia ter colocado ele na APAE. Lá, ele aprendeu a ficar bobo, ele aprendeu babar, ele aprendeu não querer falar. Eu fiquei culpada que eu não devia ter feito aquilo. Eu devia ter procurado uma escola" (Entrevistada 9).

"Ele estuda na APAE, por que como você vai colocar uma criança assim numa escola regular?" (Entrevistada 5).

\section{Influência de valores que regem a família}

Estratégias de enfretamento de natureza religiosa/espiritual foram frequentemente citadas. Observamos confiança numa vontade divina, de forma que a presença do filho com deficiência intelectual foi atribuída a um plano metafísico. A experiência de ter um filho com deficiência foi muitas vezes compreendida como missão e oportunidade de crescimento pessoal pela qual a mãe deve passar para ascender espiritualmente.

"Só Deus mesmo pra dar paciência pra gente cuidar de uma criança assim. Ajuda vem do céu" (Entrevistada 15).

"É uma benção de Deus, que Deus deu pra mim. Eu aprendi muito com isso. Deus me deu esse menino pra mudar minha vida. E como mudou..." (Entrevistada 4).

Alguns temas apreendidos denotaram ressentimento e questionamento ("Por que a mim ocorreu isso?”), sugerindo fixação no estágio de raiva do modelo de Kübler-Ross. Em outros discursos prevaleceu uma postura de minimização ou relativização da deficiência do filho em comparação a outras deficiências mais graves.

"Porque se fosse uma criança muito deficiente que não conversasse, não andasse, igual eu vejo muito por aí, pra mim ia ser mais sufocado” (Entrevistada 4).

\section{Carreira}

A interrupção da carreira materna foi tema relatado, bem como a percepção de que quando a mãe trabalha fora do lar o cuidado do filho deficiente ficava prejudicado, reforçando a ideia do cuidado centrado na mãe.

"Eu não tenho condição de trabalhar fora porque não tem quem fica com ele. Eu trabalhava, mas depois eu larguei porque não tava dando certo" (Entrevistada 4). 


\section{Lazer e recreação}

Apesar da complexidade, as famílias tentaram preservar as atividades de lazer e recreação se reorganizando para satisfazer todos os membros, considerando inclusive que o filho com deficiência intelectual possui interesses particulares e requer supervisão nas atividades recreacionais.

"Você vai só onde ela quer, só onde é interessante pra ela. Essa interação ainda é difícil, as vontades dela prevalecem, os lugares... E quando você tem outro filho, o lugar que é interessante pra um não é interessante pro outro. Então, às vezes a gente acaba tendo de separar a família. Eu digo para meu marido: 'vai você com ela, que eu vou com ele em outro lugar"' (Entrevistada 3).

\section{Interação com a comunidade}

Comportamentos do deficiente considerados anômalos foram percebidos no convívio social (em ambientes como escolas, igrejas e shoppings) e resultaram em preconceito. Dificuldades na interação comunitária foram apontadas como contribuindo para o prejuízo nas atividades de lazer.

"Você sai e todo mundo fica olhando: 'por que seu filho é assim?', 'por que não anda direito?', 'por que fica babando?', 'por que fica com a boca aberta?' É chato. Você fica chateada. Ele mesmo fala: 'por que o pessoal fica tudo olhando pro meu lado?"' (Entrevistada 4).

\section{Discussão}

Para explicar o impacto da presença de um filho com deficiência intelectual moderada na qualidade de vida familiar, sistematizamos dois processos de funcionamento familiar, complexos e inter-relacionados, que emergiram dos resultados.

No primeiro processo, relacionado à dinâmica e às características internas das famílias, o cuidado do filho deficiente esteve fortemente centrado na mãe. A presença da deficiência intelectual interferiu na qualidade da relação conjugal, cuja contribuição para o bem-estar de pais de crianças com deficiências já foi documentada 24,25,26. Os resultados mostraram que nesse processo de adaptação familiar existe rígida divisão de papéis entre os membros e, normalmente, cabe ao gênero feminino a maior carga de responsabilidade na manutenção da harmonia familiar. É importante ressaltar que papéis familiares rígidos podem colocar em risco a capacidade de adaptação intrafamiliar, prejudicando o funcionamento da família 27.

A intensa simbiose entre mãe e filho com deficiência intelectual, que já foi relatada em estudos prévios 28,29 , interferiu na relação com os demais filhos. Corroborando nossos achados, um trabalho australiano apontou que irmãos de indivíduos com deficiência intelectual compartilham o sentimento de não receber atenção suficiente e de terem suas responsabilidades aumentadas precocemente 30 . Similarmente, um estudo desenvolvido na Índia demonstrou que a qualidade de vida de irmãos de pacientes com doenças neurológicas crônicas era comprometida, com prejuízo nas atividades cotidianas relacionadas ao trabalho e estudo, e descontentamento com o padrão de sono 31 . Efeitos positivos para os irmãos de deficientes também já foram relatados e incluem desenvolvimento de características de personalidade, como compaixão, tolerância e consciência da diferença 32. É importante considerar as implicações desses resultados no papel de cuidador do indivíduo com deficiência intelectual que os irmãos poderão exercer no futuro. Profissionais de saúde devem atentar não somente para o cuidado do deficiente, mas reconhecer e procurar atuar perante as necessidades dos outros membros da família. Idealmente, todos deveriam ter acesso a sessões de terapia familiar, intervenção capaz de melhorar o funcionamento da unidade familiar, facilitando o fornecimento de informações e o desenvolvimento de estratégias de enfrentamento positivas.

Como em outros estudos, o cuidado do filho deficiente foi comparado a uma luta 33,34 e interferiu diretamente na saúde física e psicológica das mães 35,36,37. Percebemos que as mães veem a si mesmas como protetoras dos seus filhos e se sentem pessoalmente responsáveis pelos fracassos no cuidado à saúde e na educação, o que parece ser desmoralizante e contribuir para o sentimento de culpa parental.

É interessante observar que muitas mães desenvolveram uma narrativa de reconciliação, na qual a deficiência intelectual passou a ser considerada uma benção, uma oportunidade de autoconheci- 
mento e crescimento pessoal. Assim como na pesquisa de Michie \& Skinner ${ }^{38}$, realizada com mães de pacientes com síndrome de X-frágil, sentimentos de predestinação foram comuns. Estratégias de enfrentamento (coping) religioso ou espiritual normalmente contribuem para a compreensão de eventos estressores como parte de um propósito mais amplo, instaurados por uma força superior que determina os acontecimentos da vida ${ }^{39}$. No nosso trabalho houve predomínio de enfrentamento religioso do tipo renúncia, caracterizado pela escolha ativa do indivíduo de renunciar à sua vontade em favor da vontade de Deus 40. Estudos prévios evidenciaram que religião e fé são aspectos importantes no ajuste familiar a situações de deficiência 41,42,43. Dessa forma, pode ser interessante a valorização de crenças religiosas habituais da família 44. Ressalte-se, contudo, que especialmente entre indivíduos com baixa escolaridade, o enfrentamento religioso pode ser usado como único recurso para explicar os eventos adversos que ocorrem na vida 45,46. Isso pode ter acontecido no nosso estudo, já que mais da metade das participantes não concluíram o ensino médio. É importante, portanto, que profissionais de saúde disponibilizem outras possíveis explicações para a deficiência intelectual, de natureza distinta da religiosa, como as médico-científicas. De qualquer forma, a utilização de estratégias de enfretamento religioso em situações de deficiência é um aspecto que merece estudos mais aprofundados, tendo em vista que a população brasileira é muito mística e religiosa.

Um segundo processo de funcionamento familiar esteve mais intimamente ligado a aspectos significativos do meio ambiente e do contexto social a que as famílias pertenciam. As escolas, principal instituição comunitária para crianças e adolescentes, foram consideradas absurdamente inadequadas, o que repercutiu negativamente na qualidade de vida das famílias investigadas, cujos filhos com deficiência intelectual estavam predominantemente na idade escolar (entre 6 e 18 anos). O cuidado em saúde, apesar de consumir parte considerável do orçamento familiar, também foi percebido como inadequado. Dificuldades na obtenção de informações e no acesso a serviços de saúde e educação, somadas à percepção de que a qualidade dos cuidados prestados é insatisfatória, resultam em sentimentos de impotência e representam grande fonte de estresse familiar 47,48,49. Uma medida prática a ser adotada é a capacitação dos professores e dos profissionais de saúde, especialmente aqueles que atuam nos cenários de atenção primária, para o atendimento de deficientes.

Ao mesmo tempo em que há gastos financeiros com as necessidades de saúde e educação de seus filhos deficientes, as mães frequentemente abandonaram o mercado de trabalho, o que contribuiu para o empobrecimento familiar. Na população dos Estados Unidos, estima-se que mais da metade das famílias que possuem um membro com deficiência intelectual vivenciam dificuldades financeiras, e cerca de 25 a 50\% dos cuidadores interrompem suas carreiras profissionais 50,51.

O trabalho materno representa também a oportunidade de interação social e autoafirmação. O afastamento das atividades laborais pode colaborar para o desenvolvimento de sentimentos de isolamento, incompletude e baixa autoestima 52 . A inserção dessas cuidadoras no mercado de trabalho, em atividades que atendam suas demandas pessoais e respeitem a sua realidade, é uma ação política que pode impactar positivamente na qualidade de vida familiar.

Limitações financeiras, dificuldades para coordenar as agendas e os interesses dos diferentes membros da família, foram aspectos identificados como complicadores do lazer familiar, assim como no estudo de Mactavish \& Schleien 53. A interação com a comunidade também foi prejudicada em função da percepção de preconceito, que intimidou familiares e deficientes. A carência de relações interpessoais entre deficientes está associada à baixa autoestima e satisfação pessoal 48,54. A autoimagem de deficientes é afetada positivamente quando há sentimento de serem necessários e úteis para outras pessoas, o que indica importância do sentimento de pertencimento dos indivíduos com deficiência intelectual a um grupo 48 .

Nesse sentido, algumas participantes valorizaram o convívio com outras famílias que também têm filhos com deficiência intelectual. Fomentar a criação de grupos de apoio, empoderando os pacientes e suas famílias, pode ser uma boa estratégia de enfretamento. Muitas vezes, esse tipo de contato é considerado maior fonte de informações sobre a deficiência intelectual do que os próprios serviços especializados 55. O suporte extrafamiliar não tem apenas a função de promover amparo; trata-se de uma ferramenta capaz de reconhecer as necessidades familiares, fornecendo bases para se traçar estratégias de superação 13,56.

Em consonância com outras pesquisas 49,57,58,59, nosso estudo revelou que os deficientes recebem menos serviços e suportes do que realmente necessitam, nas áreas de saúde, educação e lazer. Políti- 
cas públicas sociais mais eficientes na distribuição de renda e no acesso a serviços adequados podem contribuir para a equidade.

Em síntese, identificamos dois tipos principais de apoios necessários para melhorar a dinâmica e aumentar a qualidade de vida de famílias que têm um filho com deficiência intelectual moderada. De um lado, é imperativo o acesso a apoio emocional e psicológico para todos os membros da família, que deveriam participar de terapia familiar. Por outro, medidas de apoio prático e social, que incluam distribuição de renda, capacitação de profissionais de saúde e educação, e acesso a serviços de reabilitação e lazer, são essenciais para o provimento de segurança e bem-estar social ao deficiente e sua família.

\section{Limitações do estudo}

Esta pesquisa reflete a influência de aspectos socioeconômicos e culturais. Diante da diversidade de realidades, espera-se a interferência de outros determinantes no construto de qualidade de vida em famílias que vivem em contextos diferentes.

Nossos resultados estão fundamentados na perspectiva materna, não incluindo o ponto de vista paterno em relação à dinâmica familiar. Isso se justifica porque, historicamente, as mulheres têm sido a principais responsáveis pelo cuidado dos filhos e, portanto, as mais diretamente afetadas pela deficiência 60 . No entanto, reconhecemos que os pais podem desempenhar um papel importante na educação e no cuidado de filhos com deficiência intelectual.

Além disso, os resultados são circunscritos com base na técnica de coleta de dados empregada e dentro das possibilidades de interação cognitiva e afetiva entre participantes e pesquisadores, considerando inclusive os limites interpretativos destes últimos.

\section{Colaboradores}

R. V. V. Tomaz colaborou com a elaboração do projeto de pesquisa, trabalhou na análise e interpretação dos resultados, na redação e na revisão final do manuscrito. V. A. Santos coletou os dados, colaborou na interpretação dos resultados, na redação e na revisão final do manuscrito. L. R. S. Avó colaborou na interpretação dos resultados, na redação e na revisão final do manuscrito. C. M. R. Germano colaborou na análise e interpretação dos resultados, na redação e na revisão final do manuscrito. D. G. Melo elaborou e coordenou o projeto de pesquisa, orientou a coleta de dados, trabalhou na análise e interpretação dos resultados, na redação e na revisão final do manuscrito.

\section{Agradecimentos}

Às participantes da pesquisa, que voluntariamente forneceram os dados para esta investigação. À Fundação de Amparo à Pesquisa do Estado de São Paulo (Fapesp), pelo apoio financeiro por meio dos processos 2013/24910-6 e 2013/24498-8. 


\section{Referências}

1. American Psychiatric Association. Manual diagnóstico e estatístico de transtornos mentais - DSM-5. Porto Alegre: Editora Artmed; 2014.

2. Moeschler JB. Genetic evaluation of intellectual disabilities. Semin Pediatr Neurol 2008; 15:2-9.

3. Schalock RL, Borthwick-Duffy SA, Bradley VJ, Buntinx WHE, Coulter DL, Craig EM, et al. Intellectual disability: definition, classification, and systems of supports. 11th Ed. Washington DC: American Association on Intellectual and Developmental Disabilities; 2010.

4. Instituto Brasileiro de Geografia e Estatística. Censo demográfico 2010. http://www. ibge.gov.br/home/estatistica/populacao/cen so2010/ (acessado em 06/Fev/2017).

5. Tomaz RVV, Rosa TL, Van DB, Melo DG. Políticas públicas de saúde para deficientes intelectuais no Brasil: uma revisão integrativa. Ciênc Saúde Coletiva 2016; 21:155-72.

6. Brown I, Brown RI. Quality of life and disability: an approach for community practitioners. London: Jessica Kingsley Publishers; 2003.

7. Wang M, Kober R. Embracing an era of rising family quality of life research. J Intellect Disabil Res 2011; 55:1093-7.

8. White JM, Klein DM. Family theories. 3rd Ed. Thousand Oaks: Sage Publications; 2007.

9. Bertelli M, Bianco A, Rossi M, Scuticchio D, Brown I. Relationship between individual quality of life and family quality of life for people with intellectual disability living in Italy. J Intellect Disabil Res 2011; 55:1136-50.

10. Schermerhorn AC, Cummings EM. Transactional family dynamics: a new framework for conceptualizing family influence processes. Adv Child Dev Behav 2008; 36:187-250.

11. Turnbull AP, Summers JA, Lee SH, Kyzar K. Conceptualization and measurement of family outcomes associated with families of individuals with intellectual disabilities. Ment Retard Dev Disabil Res Rev 2007; 13:346-56.

12. Samuel PS, Rillotta F, Brown I. Review: the development of family quality of life concepts and measures. J Intellect Disabil Res 2012; 56:1-16.

13. Werner S, Edwards M, Baum N, Brown I, Brown RI, Isaacs BJ. Family quality of life among families with a member who has an intellectual disability: an exploratory examination of key domains and dimensions of the revised FQOL Survey. J Intellect Disabil Res 2009; 53:501-11.

14. Ajuwon PM, Brown I. Family quality of life in Nigeria. J Intellect Disabil Res 2012; 56:61-70.

15. Hu X, Wang M, Fei X. Family quality of life of Chinese families of children with intellectual disabilities. J Intellect Disabil Res 2012; 56: 30-44.

16. Fundação Sistema Estadual de Análise de Dados. Informação dos municípios paulistas. http:// www.imp.seade.gov.br/ (acessado em 06/Fev/ 2017).
17. Campos CJ, Turato ER. Content analysis in studies using the clinical-qualitative method: application and perspectives. Rev Latinoam Enferm 2009; 17:259-64.

18. Turato ER. Tratado de metodologia da pesquisa clínico-qualitativa: construção teórico-epistemológica, discussão comparada e aplicação nas áreas da saúde e humanas. Petrópolis: Vozes Editora; 2008.

19. Fontanella BJB, Ricas J, Turato ER. Amostragens por saturação em pesquisas qualitativas: contribuições teóricas. Cad Saúde Pública 2008; 24:17-27.

20. Fontanella BJB, Luchesi BM, Saidel MGB, Ricas J, Turato ER, Melo DG. Amostragem em pesquisas qualitativas: proposta de procedimentos para constatar saturação teórica. Cad Saúde Pública 2011; 27:388-94.

21. Fontanella BJ, Campos CJ, Turato ER. Data collection in clinical-qualitative research: use of non-directed interviews with open-ended questions by health professionals. Rev Latinoam Enferm 2006; 14:812-20.

22. Bardin L. Análise de conteúdo. São Paulo: Edições 70; 2011.

23. Campos CJG. Método de análise de conteúdo: ferramenta para a análise de dados qualitativos no campo da saúde. Rev Latinoam Enferm 2004; 57:611-4.

24. Kersh J, Hedvat TT, Hauser-Cram P, Warfield ME. The contribution of marital quality to the well-being of parents of children with developmental disabilities. J Intellect Disabil Res 2006; 50:883-93.

25. Lickenbrock DM, Ekas NV, Whitman TL. Feeling good, feeling bad: influences of maternal perceptions of the child and marital adjustment on well-being in mothers of children with an autism spectrum disorder. J Autism Dev Disord 2011; 41:848-58.

26. Kwok SY, Leung CL, Wong DF. Marital satisfaction of Chinese mothers of children with autism and intellectual disabilities in Hong Kong. J Intellect Disabil Res 2014; 58:1156-71.

27. Sprovieri MHS, Assumpção Jr. FB. Dinâmica familiar de crianças autistas. Arq Neuropsiquiatr 2001; 59:230-7.

28. Falkenbach AP, Drexsler G, Werler V. The relation mother/child with disabilities: feelings and experiences. Ciênc Saúde Coletiva 2008; 13:2065-73.

29. Barbosa MAM, Chaud MN, Gomes MMF. Vivências de mães com um filho deficiente: um estudo fenomenológico. Acta Paul Enferm 2008; 21:46-52.

30. Rillotta F, Kirby N, Shearer J, Nettelbeck T. Family quality of life of Australian families with a member with an intellectual/developmental disability. J Intellect Disabil Res 2012; 56:71-86.

31. Rana P, Mishra D. Quality of life of unaffected siblings of children with chronic neurological disorders. Indian J Pediatr 2015; 82:545-8. 
32. Dyke P, Mulroy S, Leonard H. Siblings of children with disabilities: challenges and opportunities. Acta Paediatr 2009; 98:23-4.

33. Redmond B, Richardson V. Just getting on with it: exploring the service needs of mothers who care for young children with severe/profound and life-threatening intellectual disability. J Appl Res Intellect Disabil 2003; 16:205-18.

34. Chadwick DD, Mannan H, Garcia Iriarte E, McConkey R, O’Brien P, Finlay F, et al. Family voices: life for family carers of people with intellectual disabilities in Ireland. J Appl Res Intellect Disabil 2013; 26:119-32.

35. Raina P, O’Donnell M, Rosenbaum P, Brehaut J, Walter SD, Russell D, et al. The health and well-being of caregivers of children with cerebral palsy. Pediatrics 2005; 115:e626-36.

36. Laurvick CL, Msall ME, Silburn S, Bower C, de Klerk N, Leonard H. Physical and mental health of mothers caring for a child with Rett syndrome. Pediatrics 2006; 118:e1152-64.

37. Miodrag N, Hodapp RM. Chronic stress and health among parents of children with intellectual and developmental disabilities. Curr Opin Psychiatry 2010; 23:407-11.

38. Michie M, Skinner D. Narrating disability, narrating religious practice: reconciliation and fragile X syndrome. Intellect Dev Disabil 2010; 48:99-111.

39. Panzini RG, Bandeira DR. Coping (enfrentamento) religioso/espiritual. Rev Psiquiatr Clín 2007; 34:126-35.

40. Pargament KI, Koenig HG, Perez LM. The many methods of religious coping: development and initial validation of the RCOPE. J Clin Psychol 2000; 56:519-43.

41. Rogers-Dulan J. Religious connectedness among urban African American families who have a child with disabilities. Ment Retard 1998; 36:91-103.

42. Skinner DG, Correa V, Skinner M, Bailey Jr. DB. Role of religion in the lives of Latino families of young children with developmental delays. Am J Ment Retard 2001; 106:297-313.

43. Miltiades HB, Pruchno R. The effect of religious coping on caregiving appraisals of mothers of adults with developmental disabilities. Gerontologist 2002; 42:82-91.

44. Faria JB, Seidl EMF. Religiosidade e enfrentamento em contextos de saúde e doença: revisão da literatura. Psicol Reflex Crít 2005; 18:381-9.

45. Levin JS, Chatters LM. Religion, health, and psychological well-being in older adults: findings from three national surveys. J Aging Health 1998; 10:504-31.

46. Tedrus GM, Fonseca LC, De Pietro Magri F, Mendes PH. Spiritual/religious coping in patients with epilepsy: relationship with sociodemographic and clinical aspects and quality of life. Epilepsy Behav 2013; 28:386-90.

47. Nowak HI, Broberg M, Starke M. Parents' experience of support in Sweden: its availability, accessibility, and quality. J Intellect Disabil 2013; 17:134-44
48. Morisse F, Vandemaele E, Claes C, Claes L, Vandevelde S. Quality of life in persons with intellectual disabilities and mental health problems: an explorative study. ScientificWorldJournal 2013; 2013:491918.

49. Beadle-Brown J, Leigh J, Whelton B, Richardson L, Beecham J, Baumker T, et al. Quality of life and quality of support for people with severe intellectual disability and complex needs. J Appl Res Intellect Disabil 2016; 29:409-21.

50. Ouyang L, Grosse SD, Riley C, Bolen J, Bishop E, Raspa M, et al. A comparison of family financial and employment impacts of fragile $\mathrm{X}$ syndrome, autism spectrum disorders, and intellectual disability. Res Dev Disabil 2014; 35:1518-27.

51. Saunders BS, Tilford JM, Fussell JJ, Schulz EG, Casey PH, Kuo DZ. Financial and employment impact of intellectual disability on families of children with autism. Fam Syst Health 2015; 33:36-45.

52. Shearn J, Todd S. Maternal employment and family responsibilities: the perspectives of mothers of children with intellectual disabilities. J Appl Res Intellect Disabil 2000; 13: 109-31.

53. Mactavish JB, Schleien SJ. Re-injecting spontaneity and balance in family life: parents' perspectives on recreation in families that include children with developmental disability. J Intellect Disabil Res 2004; 48:123-41.

54. Lucas-Carrasco R, Salvador-Carulla L. Life satisfaction in persons with intellectual disabilities. Res Dev Disabil 2012; 33:1103-9.

55. Knox M, Parmenter TR, Atkinson N, Yazbec M. Family control: the views of families who have a child with an intellectual disability. J Appl Res Intellect Disabil 2000; 13:17-28.

56. Rosenthal ET, Biesecker LG, Biesecker BB. Parental attitudes toward a diagnosis in children with unidentified multiple congenital anomaly syndromes. Am J Med Genet 2001; 103: 106-14.

57. Bouras N. Unmet needs of people with developmental and intellectual disability. Curr Opin Psychiatry 2010; 23:405-6.

58. Vilaseca R, Gràcia M, Beltran FS, Dalmau M, Alomar E, Adam-Alcocer AL, et al. Needs and supports of people with intellectual disability and their families in Catalonia. J Appl Res Intellect Disabil 2017; 30:33-46.

59. Verdonschot MM, de Witte LP, Reichrath E, Buntinx WH, Curfs LM. Impact of environmental factors on community participation of persons with an intellectual disability: a systematic review. J Intellect Disabil Res 2009; 53:54-64.

60. Shapiro J, Blacher J, Lopez SR. Maternal reactions to children with mental retardation. In: Burack JA, Hodapp RM, Zigler E, edirors. Handbook of mental retardation and development. Cambridge: Cambridge University Press; 1998. p. 606-36. 


\section{Abstract}

This qualitative clinical study investigated the impact of moderate intellectual disability on family dynamics and quality of life. The data were collected using individual interviews with 15 mothers of children with intellectual disabilities, as a convenience sample, and examined with categorical thematic content analysis. The results were discussed using a comprehensive and interpretative approach. Analysis of the interviews showed that care for children with intellectual disabilities is centered on the mother, contributing to the change in family relations. Religious coping appeared as a common strategy for adjusting. Children with intellectual disabilities had less access to services and support than they needed in the areas of health, education, and leisure. Financial constraints and difficulties in community living had a negative impact on the quality of family life. Emotional and psychological support for all the family members, and practical and social support, including income distribution and access to adequate services, proved essential for the well-being of children with intellectual disabilities and their families.

Intellectual Disability; Family Relations; Qualitative Research

\section{Resumen}

Este estudio clínico-cualitativo investigó el impacto de la deficiencia intelectual moderada en la dinámica y en la calidad de vida familiar. Los datos se recogieron mediante entrevistas individuales con 15 madres de deficientes, escogidas por conveniencia, y examinadas por la técnica de análisis de contenido categorial temático. Los resultados se discutieron usándose un enfoque comprensivo e interpretativo. Del análisis de las entrevistas se aprendió que el cuidado del hijo deficiente está centrado en la madre, lo que contribuyó a la modificación de las relaciones familiares. El enfrentamiento religioso apareció como estrategia común de ajuste. Los hijos deficientes tuvieron acceso a menos servicios y apoyos de los que necesitaban, en las áreas de salud, educación y ocio. Restricciones financieras y dificultades en la convivencia comunitaria impactaron negativamente en la calidad de vida familiar. Apoyo emocional y psicológico para todos los miembros de la familia, y apoyo práctico y social, incluyendo distribución de renta y acceso a servicios adecuados, se mostraron esenciales para el bienestar del deficiente y de su familia.

Discapacidad Intelectual; Relaciones Familiares; Investigación Cualitativa
Recebido em 02/Jun/2016

Versão final reapresentada em 07/Fev/2017

Aprovado em 08/Mar/2017 